\title{
Severe Obesity in Children and Adolescents: Metabolic Effects, Assessment, and Treatment
}

\author{
Yoojin Lindsey Chung', Young-Jun Rhie ${ }^{2, *}$ \\ 'Department of Pediatrics, Myongji Hospital, Hanyang University Medical Center, Goyang; ${ }^{2}$ Department of Pediatrics, Korea University Ansan Hospital, Ansan, Korea
}

Childhood obesity has been increasing steadily in recent decades, and severe childhood obesity has emerged as a major public health problem both nationally and internationally. A current concern is that lockdown due to the coronavirus disease 2019 (COVID-19) pandemic could exacerbate the spread of childhood obesity and increase the gap in obesity risk. Recent research results indicate the aggravation of obesity after school closures. The consequences of severe childhood obesity are more devastating than those of mild to moderate obesity. Children with severe obesity are at greater risk than others for hypertension, type 2 diabetes, metabolic syndrome, non-alcoholic fatty liver disease, atherosclerosis, and adult obesity. Accurately assessing and diagnosing a child with severe obesity is the key to implementing successful therapy. A detailed and accurate patient history and physical examination are important to discriminate monogenic obesity and metabolic syndrome diagnoses from severe obesity without an underlying cause. Psychosocial factors, including eating behaviors, should be assessed to facilitate better weight management outcomes. Treatment options for severe pediatric obesity include lifestyle modification therapy, pharmacotherapy, and metabolic and bariatric surgery. However, lifestyle modification should be the priority. Although progress has been made, safe and effective treatment for severe pediatric obesity is still challenging. More efforts and innovations are needed to find a solution for the huge medical and emotional burden that these children and their families carry. Public health organizations also need to make efforts to encourage and normalize healthy eating habits and exercise to prevent severe obesity in childhood.
Received July 22, 2021

Reviewed December 6, 2021

Accepted December 7, 2021

*Corresponding author

Young-Jun Rhie

(iD) https://orcid.org/0000-0002-1250-6469

Department of Pediatrics, Korea University Ansan Hospital, 123 Jeokgeum-ro, Danwon-gu, Ansan 15355, Korea

Tel: +82-31-412-4846

Fax: +82-31-405-8591

E-mail:human21@korea.ac.kr

Key words: Pediatric obesity, Obesity morbid, Obesity management, Healthy lifestyle

\section{INTRODUCTION}

The prevalence of pediatric obesity has increased dramatically during the past forty years in Korea and worldwide. ${ }^{1,2}$ Although recent data suggest that the increase in pediatric obesity has slowed and its overall prevalence has begun to stabilize, severe pediatric obesity continues to increase consistently., The overall prevalence of severe pediatric obesity in Korea increased from $1.2 \%-1.8 \%$ in 2001 to $2.1 \%-2.4 \%$ in $2013-2014 .^{4}$ The coronavirus disease 2019 (COVID-19) pandemic is causing long-term school closures, which could be exacerbating the spread of childhood obesity and increasing the gap in obesity risk. ${ }^{5,6}$ Indeed, according to recent reports, re- duced physical activity due to school closures during the COVID19 pandemic is aggravating obesity and glucose intolerance in children and adolescents with obesity. ${ }^{6-8}$ Low socioeconomic status (SES) significantly affects pediatric obesity. Many studies have reported that SES is associated with a risk of obesity in both adults and children because it can influence lifestyle factors such as food choices and physical activities. ${ }^{9,10}$ A consistent association between low SES and obesity has been reported in Korean studies. ${ }^{11,12}$

Pediatric obesity is associated with numerous comorbidities, such as type 2 diabetes mellitus (T2DM), hypertension, dyslipidemia, non-alcoholic fatty liver disease (NAFLD), obstructive sleep apnea, polycystic ovary syndrome (PCOS), and psychiatric problems in

Copyright (C) 2021 Korean Society for the Study of Obesity

(a) This is an Open Access article distributed under the terms of the Creative Commons Attribution Non-Commercial License (https://creativecommons.org/licenses/by-nc/4.o/) which permits unrestricted non-commercial use, distribution, and reproduction in any medium, provided the original work is properly cited. 
childhood. ${ }^{13-16}$ Children with severe obesity have more adverse cardiometabolic risks than children who are overweight or have mild to moderate obesity. Early signs of vascular dysfunction and subclinical atherosclerosis have also been reported in children with severe obesity. ${ }^{17-19}$ When adiposity was tracked from childhood into adulthood, the degree of retained adiposity was stronger in cases of severe childhood obesity. ${ }^{20,21}$ Therefore, preventing and treating severe pediatric obesity is important to prevent and attenuate the risk of preclinical atherosclerosis. ${ }^{21}$

In this article, we focus on ways to assess pediatric patients with severe obesity and outline the main therapeutic approaches used to treat severe childhood obesity: lifestyle modification therapy, pharmacotherapy, and metabolic and bariatric surgery (MBS).

\section{DEFINITION OF OBESITY AND SEVERE OBESITY IN CHILDHOOD}

Most adult obesity begins in childhood, ${ }^{22,23}$ making pediatric obesity a concern and giving impetus to medical professionals to prevent and treat childhood obesity. Body mass index (BMI) is the acknowledged indicator of obesity in both children and adults. ${ }^{24}$ Using normal BMI curves for age and sex in children, a BMI at or above the 85th percentile and below the 95th percentile is categorized as overweight, and a BMI at or above the 95 th percentile is categorized as obesity. Obesity is further divided into three classes by using the 95th percentile for age and sex as the reference value and categorizing $100 \%$ to $120 \%$ of the 95 th percentile as class I obesity, $120 \%$ to $140 \%$ as class II obesity, and more than $140 \%$ as class III obesity (Table 1). ${ }^{3,25,26}$ Severe pediatric obesity is defined as class II and III obesity. Cardiometabolic risk increases with rising degrees of obesity, and class II and III obesity have a strong association with these risks. ${ }^{25}$

\section{METABOLIC EFFECTS OF SEVERE PEDIATRIC OBESITY}

In pediatric obesity, metabolic and cardiovascular complications are observed during childhood and are closely related to the development of insulin resistance, which is the most widely recognized biochemical change in obesity. ${ }^{27}$ The comorbidities related to obe-
Table 1. Pediatric definitions of overweight, obesity, and severe obesity ${ }^{26}$

\begin{tabular}{ll}
\hline Weight status category & \multicolumn{1}{c}{ Percentile range } \\
\hline Overweight & 85 th $-<95$ th percentile \\
Obesity/class I & $100 \%-120 \%$ of the 95 th percentile \\
Severe obesity/class II & $120 \%-140 \%$ of the 95 th percentile \\
Severe obesity/class III & $>140 \%$ of the 95 th percentile \\
\hline
\end{tabular}

sity from early childhood are glucose intolerance, dyslipidemia, and hypertension. The cluster of these medical conditions is called metabolic syndrome, or insulin resistance syndrome, and includes T2DM, hypertension, dyslipidemia, and coronary heart disease. ${ }^{28}$

Insulin resistance is defined as a decreased tissue response to insulin-mediated cellular actions and is the inverse of insulin sensitivity. The insulin resistance seen in obesity does not affect all tissues equally because insulin affects the liver, adipose tissues, and muscle in different ways. Insulin in the liver diminishes hepatic glucose production and increases the transcription of genes required for fatty acid and triglyceride biosynthesis. Insulin-resistant subjects can have selective hepatic insulin resistance, which is impaired glucose homeostasis but normal insulin-mediated hepatic de novo lipogenesis. ${ }^{29,30}$ The resulting increase in free fatty acid (FFA) flux within the liver impairs hepatic insulin action via fatty acyl-CoA intermediates within hepatocytes, ${ }^{31}$ which increases hepatic glucose output, the synthesis of proinflammatory cytokines, and triglyceride secretion by the liver; lowers high-density lipoprotein cholesterol levels; and increases relatively cholesterol-depleted lowdensity lipoprotein particles. ${ }^{32}$ Furthermore, the intrahepatic accumulation of FFA and lipids is itself detrimental to liver insulin sensitivity. ${ }^{33}$ Intrahepatic insulin resistance results in greater first-pass insulin clearance in the liver, which lowers the amount of insulin reaching systemic circulation. The expanded adipose tissue mass that accompanies obesity leads to increased lipolysis and FFA turnover.

Insulin resistance accelerates the lipolytic process, leading to increased FFA release into the circulation. Moreover, visceral adipocytes are more sensitive to catecholamine-stimulated lipolysis than subcutaneous adipocytes, which further increases FFA release. ${ }^{34} \mathrm{~A}$ greater FFA concentration following an oral glucose load worsens glucose tolerance. ${ }^{35}$ Increased plasma FFA flux into skeletal muscle results in fatty acyl-CoA derivatives that alter the insulin signal transduction pathway and reduce insulin-mediated glucose trans- 
port in skeletal muscle, further facilitating the development of hyperglycemia. ${ }^{33}$ Intramyocellular lipid deposition is tightly associated with insulin resistance and has been detected in children with obesity who have altered glucose metabolism. ${ }^{36,37}$

The risk of the metabolic syndrome is higher in teenage boys with severe obesity than girls, as shown by a Korean population study, which found that the rates of metabolic syndrome in obese teenage boys were more than double those in girls, which is consistent with a prior study from the United States. ${ }^{4,25}$

\section{ASSESSMENT OF SEVERE PEDIATRIC OBESITY}

When an accurate diagnosis is made and complications are properly identified, severe pediatric obesity can be treated successfully. A thorough medical history from birth to the present should be taken, including birth weight, BMI of both parents, exposure to gestational diabetes, maternal obesity, prematurity, history of breastfeeding, neonatal complications, neurodevelopmental abnormalities, signs of dysmorphism, and medication use, especially glucocorticoids, antiepileptics, and antipsychotics. Orthopedic problems, headaches, and snoring must also be assessed. It is very important to identify the potential underlying contributors to metabolic dysregulation because obesity is a heterogeneous disease. ${ }^{38} \mathrm{In}$ a physical examination, linear growth gives clues that can be used to exclude organic causes of obesity; however, hyperinsulinemia and insulin resistance can cause accelerated growth through crossreactivity between insulin and the insulin-like growth factor 1 receptor. ${ }^{39}$ Acanthosis nigricans and waist circumference are important physical features because both clinical characteristics are correlated with insulin resistance and metabolic syndrome.

A laboratory evaluation should be conducted and assessed for obesity-related comorbidity markers, including aspartate aminotransferase, alanine aminotransferase, lipids, fasting glucose, and hemoglobin Alc. Luteinizing hormone, follicular-stimulating hormone, and testosterone levels should be examined to evaluate delayed puberty in boys and PCOS in girls. ${ }^{40}$ An oral glucose tolerance test for T2DM could be necessary when familial risk factors are present. ${ }^{40}$

\section{Biological factors}

Genetics is the greatest contributor to obesity, and 30\%-90\% of genetic variation in BMI is heritable. ${ }^{41}$ Simple obesity arises through the additive effects of multiple genes associated with obesity. ${ }^{42}$ On the other hand, $5 \%$ to $10 \%$ of children with hyperphagia and obesity in early childhood have a monogenic condition that causes obesity; most of those cases arise from monogenic disorders of the leptin-melanocortin pathway. ${ }^{43}$ Therefore, patients with severe obesity or obesity in early childhood who also have developmental delay, dysmorphic features, short stature, or intellectual disability require a genetic evaluation. The identification of monogenic obesity could help to identify pharmacological treatments, such as setmelanotide, a melanocortin- 4 receptor agonist for proopiomelanocortin, or proprotein convertase subtilisin/kexin type 1 or leptin, a hormone related to satiety, for leptin receptor deficiency, ${ }^{44}$ and direct further evaluations for other comorbidities, including organ-specific anomalies. Other biological factors, including endocrine disorders such as growth hormone deficiency, hypothyroidism, and Cushing syndrome, should also be evaluated.

Eating behaviors are an additional determining factor of obesity. In addition to the typical assessment of dietary components, such as the frequency of fast food or sugar-sweetened beverage consumption, a thorough and detailed history of eating behaviors can provide information about the etiology of obesity. For example, children who are described as always having food in their mouths, eating adult portion sizes, or eating snacks between meals might have impaired homeostatic appetite control. ${ }^{45}$ On the other hand, non-homeostatic mechanisms that contribute to obesity are suggested in patients who emotionally overeat to deal with negative emotions or stressful situations (hedonic hunger).

A low level of physical activity and sedentary lifestyle is another biological contributor to severe pediatric obesity. Obese children might hesitate to exercise, in part, because of musculoskeletal pain, developmental delays in gross motor skills, poor cardiorespiratory fitness, or depression. Insufficient sleep quantity due to the use of an electronic device late at night or poor sleep quality caused by obstructive sleep apnea or central hypoventilation syndrome increase the level of ghrelin, a hunger hormone, and cortisol and decrease the response to leptin, a satiety hormone, making a body prone to obesity. ${ }^{46,47}$ 


\section{Psychosocial factors}

Obese children, especially those looking for obesity treatment, have a greater tendency than normal-weight children to have psychological problems such as depression, anxiety, attention deficit hyperactive disorder (ADHD), and eating disorders. ${ }^{48}$ The incidence of depression is three times higher and anxiety is five times higher in adolescents with severe obesity than in those with moderate obesity. ${ }^{49}$ The prevalence of binge eating is reported to be higher in children with severe obesity (17\%) than mild to moderate obesity $(10 \%) .^{50}$ Therefore, assessing those symptoms and offering proper treatment is important in clinical practice to facilitate better weight management outcomes. Simple screening tests for depression, anxiety, $\mathrm{ADHD}$, and eating disorders can be completed through questionnaires. Referral to mental healthcare should be considered in patients with positive responses.

In addition to physical health, severe obesity has negative consequences on psychosocial well-being. In a multicenter observational study, 233 adolescents completed a questionnaire about physical comfort, body esteem, social life, and family relations. The results showed that a high BMI was a negative predictor for quality of life. ${ }^{51}$ In a study of 361 youth looking for a weight loss program, the rate of weight-based victimization increased with body weight. ${ }^{52}$ Identifying when children are experiencing victimization and providing the needed support or resources in school and at home is an essential part of any obesity management plan.

\section{TREATMENT}

\section{Lifestyle modification}

Lifestyle modification therapy is essential for pediatric obesity treatment. Especially for children with severe obesity, it should be used as the first-line therapeutic option. ${ }^{26}$ Numerous treatment programs apply strategies such as dietary modification, increasing physical activity, and behavioral changes such as self-monitoring, stimulus control, positive reinforcement, social support, and cognitive behavior therapy. An essential component in the treatment of pediatric obesity is parental involvement to offer support and model healthy behavior; the family-based program is the most successful weight management program. However, even though lifestyle modification is a relevant first-line treatment, the effects appear dis- appointing in children with severe obesity. The most effective programs are correlated with only a modest reduction $(5 \%-20 \%)$ in BMI among children with severe obesity, and those effects are not durable over time. ${ }^{26}$ The treatment efficacy was related to the child's age at the onset of obesity. Thus, early treatment might be one way to reduce treatment failure during adolescence. ${ }^{53}$

Basic dietary recommendations are mostly based on low-fat diets, though recently, low-carbohydrate diets have gained popularity. ${ }^{54} \mathrm{~A}$ systematic review of 107 studies found that low-carbohydrate diets had weight loss outcomes proportionate to those of low-fat diets and did not have any particular adverse effects on serum lipids, fasting serum glucose and insulin levels, or blood pressure. ${ }^{54}$ Among the various low-carbohydrate diets, the protein-sparing modified fast diet showed marked weight reduction, especially in children and adolescents with severe obesity. This diet is a calorie reduction, lowcarbohydrate, and high-protein diet based on weight loss related to ketosis. Patients who participated in this intervention reached a mean weight reduction of $8 \mathrm{~kg}$ from baseline at 13 weeks; following a slight increase, the net weight reduction was $11 \%$ at 36 weeks. ${ }^{55}$

Meal replacement therapy is a form of low-calorie diet in which one or two full-calorie meals daily are replaced with low-calorie frozen meals, shakes, or bars. It has been used with short-term success in adolescents with severe obesity. ${ }^{56}$ These kinds of meals provide convenient portion control; however, weight regain began at the finish of therapy when a normal diet was resumed. In addition, longterm compliance is poor, and using this therapy in children might be limited by poor acceptance among both parents and patients.

Physical activity is the second most important behavioral intervention. The American Academy of Pediatrics and European Society for Pediatric Endocrinology recommend physical activity regardless of weight status, encouraging daily moderate-to-vigorous physical activity and limiting screen time to 1 to 2 hours a day. . $^{57,58}$ Most children, including children with severe obesity, do not achieve those recommendations. Exercise physiologists and physical therapists can help children by developing individual exercise plans, especially when movement is limited by gross motor delays or musculoskeletal pain. ${ }^{59}$ However, although interest in the application of physical therapy to severe obesity is increasing, many program developments are needed to apply it within the current medical system. 


\section{Pharmacotherapy}

The primary treatment option for pediatric obesity is lifestyle modification therapy. Pharmacotherapy is the next logical treatment for patients who fail to meet their weight loss goals with lifestyle modification therapy alone (Table 2). The indications for pharmacotherapy in pediatric obesity are patients aged 10 years or more and BMI $\geq 95$ th percentile with weight-related comorbidities or BMI $\geq 120 \%$ of the 95 th percentile irrespective of comorbidities who have not responded appropriately to lifestyle modification. ${ }^{58,60}$

The only medication approved by the U.S. Food and Drug Administration (FDA) for long-term use to treat pediatric obesity is orlistat ( $\geq 12$ years), a lipase inhibitor that prevents the absorption of fats from the human diet. However, its clinical use is fairly limited due to its modest efficacy (about a $2.61 \mathrm{~kg}$ reduction after 1 year of treatment) and adverse effects, which can be intolerable for many adolescents (flatulence, oily spotty stools, and diarrhea). ${ }^{61,62}$ Phentermine, a norepinephrine reuptake inhibitor, is FDA approved for short-term treatment in children older than 16 years with lifestyle modifications. The efficacy of phentermine is also relatively modest, approximately $4 \%$ BMI reduction. Phentermine is a substituted amphetamine that can cause tachycardia, hypertension, restlessness, dizziness, and trouble sleeping. ${ }^{63}$ Metformin, a biguanide primarily used for glycemic control, is FDA approved for children $\geq 10$ years of age with T2DM, and it has been used off-label to achieve weight loss in children. Masarwa et al. ${ }^{64}$ reported the efficacy of metformin in a systematic review of randomized controlled trials (RCTs) in children and adolescents. They demonstrated that metformin use offered modest benefits in BMI reduction in subjects with obesity. Among the 14 RCTs that reported BMI, metformin was modestly efficacious at decreasing it (range of mean changes, -2.70 to 1.30 ) compared with placebo (-1.12 to 1.90). Among the seven RCTs in which a BMI z-score was reported, metformin consistently resulted in a decrease in the BMI z-score (range of mean change, -0.37 to $-0.03)$ compared with placebo ( -0.22 to 0.15$)$, with largest decrease in BMI z-score in children and adolescents with NAFLD. In a metaanalysis of 616 pediatric patients that compared the use of metformin and placebo for weight reduction (BMI baseline $36.0 \mathrm{~kg} / \mathrm{m}^{2}$ and metformin dose ranging from 1 to $2 \mathrm{~g}$ per day), metformin treatment reduced the BMI $z$-score $(-0.10 ; 95 \% \mathrm{CI},-0.17$ to -0.03$)$ and BMI $(-0.86$; $95 \% \mathrm{CI},-1.44$ to -0.29$) .{ }^{65}$ Some studies reported an improvement in fasting plasma glucose and insulin resistance without a decrease in lipid levels. However, metformin was associated with a doubling of gastrointestinal adverse effects compared with placebo. ${ }^{64}$ Whether metformin is a reasonable adjunct therapy with lifestyle modification for treatment of childhood obesity remains an open question.

Table 2. Summary of medications for weight loss in the pediatric population

\begin{tabular}{|c|c|c|c|c|}
\hline Drug name & Mechanism of action & FDA indication & Off-label drug use & Consideration \\
\hline Orlistat ${ }^{61,62}$ & $\begin{array}{l}\text { Pancreatic and gastric lipase } \\
\text { inhibitor }\end{array}$ & Obesity, $\geq 12$ years of age & Not indicated & $\begin{array}{l}\text { Flatulence, oily spotty stools, diarrhea, vitamin/ } \\
\text { mineral deficiency }\end{array}$ \\
\hline Phentermine $^{63}$ & Sympathomimetic amine & $\begin{array}{l}\text { Obesity, }>16 \text { years of age for } \\
\text { "short term" use }\end{array}$ & $\begin{array}{l}<16 \text { Years of age or long term; beneficial } \\
\text { in obesity with low-energy states, sleep } \\
\text { apnea, hunger, decreased satiety }\end{array}$ & $\begin{array}{l}\text { Increases heart rate, blood pressure, dry mouth, } \\
\text { insomnia, constipation, anxiety, and irritability }\end{array}$ \\
\hline Metformin ${ }^{65}$ & $\begin{array}{l}\text { Activation of protein kinase } \\
\text { pathway }\end{array}$ & $\geq 10$ years of age, $\mathrm{T} 2 \mathrm{DM}$ & $\begin{array}{l}\text { PCOS, insulin resistance, prediabetes, } \\
\text { metabolic syndrome, antipsychotic } \\
\text { medication-induced weight gain, stress } \\
\text { eating/emotional eating }\end{array}$ & $\begin{array}{l}\text { Bloating, diarrhea, flatulence; contraindicated } \\
\text { with risk of lactic acidosis }\end{array}$ \\
\hline Exenatide 66.68 & GLP-1 agonist & T2DM in adults & $\begin{array}{l}<18 \text { Years of age for obesity (polygenic } \\
\text { with the presence of diabetes, } \\
\text { hypothalamic, syndromic) }\end{array}$ & $\begin{array}{l}\text { Bloating, nausea/vomiting, abdominal pain, } \\
\text { elevation of pancreatic amylase and lipase; } \\
\text { contraindicated with history or family history } \\
\text { of medullary thyroid carcinoma, MEN type 2, } \\
\text { ESRD }\end{array}$ \\
\hline Liraglutide ${ }^{69}$ & GLP-1 agonist & $\begin{array}{l}\text { 3.0-mg liraglutide approved for } \\
\text { obesity in adolescents (12-17 } \\
\text { years) with a reduced-calorie diet } \\
\text { and increased physical activity }\end{array}$ & Not indicated & $\begin{array}{l}\text { Gl abdominal pain, nausea, vomiting, diarrhea, } \\
\text { potential hypoglycemia; contraindicated with } \\
\text { history or family history of medullary thyroid } \\
\text { carcinoma, MEN type 2, ESRD }\end{array}$ \\
\hline
\end{tabular}

FDA, Food and Drug Administration; T2DM, type 2 diabetes mellitus; PCOS, polycystic ovary syndrome; GLP-1, glucagon-like peptide-1; MEN, multiple endocrine neoplasia; ESRD, end-stage renal disease; $\mathrm{Gl}$, gastrointestinal. 
Exenatide and liraglutide are glucagon-like peptide-1 (GLP-1) receptor agonists. Exenatide has FDA approval to treat T2DM in adults, and a liraglutide $3.0 \mathrm{mg}$ injection is FDA approved to treat obesity in adults. In December 2020, $3.0 \mathrm{mg}$ liraglutide injection achieved FDA approval to treat obesity in adolescents (12 to 17 years) whose body weight is more than $60 \mathrm{~kg}$ and initial BMI is $\geq 30 \mathrm{~kg} / \mathrm{m}^{2}$, in combination with a reduced-calorie diet and increased physical activity. GLP-1 receptor agonist-associated weight reduction appears to be related to decreased gastric emptying and increased satiety and appetite suppression. In two RCTs of adolescents and children with severe obesity, 3 months of exenatide treatment elicited a significant reduction in BMI and body weight. ${ }^{66,67} \mathrm{~A}$ 6-month doubleblind RCT of weekly exenatide in adolescents with severe obesity reported a significant reduction in BMI and improvement in glucose tolerance and cholesterol compared with placebo. ${ }^{68}$ Recently, an RCT of adolescent obesity with a 56-week liraglutide treatment period reported that $3.0 \mathrm{mg}$ liraglutide plus lifestyle modifications resulted in a significant reduction in BMI z-scores. ${ }^{69}$ GLP-1 receptor agonist therapy also has potential for weight reduction and weight stabilization in patients with syndromic and hypothalamic obesity with hyperphagia. ${ }^{70,71}$

\section{Metabolic and bariatric surgery}

surgical treatment for obesity in children and adolescents has not yet been approved as a common treatment recommendation. Little research has examined the effects of surgical treatment on growth and development in children and adolescents. Thus, it is only considered after growth and puberty are complete. Also, surgical treatment in growing children and adolescents should be limited to strict standards. Before considering surgical treatment, an evaluation of less invasive treatments, such as multidisciplinary treatment and pharmacotherapy, should be conducted. Furthermore, adolescents and their families should have psychological stability and competence, appropriate follow-up care, and a demonstrated ability to comply with healthy dietary and activity routines. It is also very important that patients have a reliable caretaker who can provide physical and psychosocial support throughout the entire process. MBS in adolescents has been shown to be an effective treatment for severe obesity, and significant resolution for obesity-associated comorbidities has been reported. ${ }^{72}$
Current guidelines issued by the American Society for Metabolic and Bariatric Surgery's Pediatric Committee suggest that MBS can be considered for children $\geq 10$ years with a BMI $\geq 120 \%$ of the 95th percentile with a weight-related comorbidity, such as T2DM, hypertension, NAFLD, or obstructive sleep apnea, or a BMI $\geq 140 \%$ of the 95 th percentile regardless of comorbidities. ${ }^{72}$ In accordance with the guidelines, adolescents with prior weight loss attempts, low Tanner stage, and immature bone growth should not be denied surgical treatment. ${ }^{72}$ However, there is a lack of data to show how a child's pubertal status, as measured by Tanner staging, linear growth, or height, is affected by MBS. Therefore, further studies should be conducted on the effects of MBS on pubertal growth in children.

The two primary procedures for MBS that have been evaluated in pediatric patients are Roux-en-Y gastric bypass (RYGB) and vertical sleeve gastrectomy (VSG). In prospective studies among adolescents with severe obesity, medium-term weight reduction (1-3 years) ranged from $30 \%$ to $40 \%$ of BMI, and long-term results (5-8 years) showed a sustainable BMI reduction of about $30 \%{ }^{73-76}$ In addition, studies of MBS in rare pediatric cases with genetic defects as the primary cause of severe obesity (Prader-Willi syndrome and melanocortin 4 receptor mutation) have shown promising BMI reduction and resolution of comorbidities. ${ }^{77,78}$

MBS has the potential to cause both macro- and micronutrient deficiency, and lifelong supplementation of protein, iron, calcium, and vitamins is required to prevent deficiencies. Because RYGB uses both restrictive and malabsorptive mechanisms for weight reduction, deficiencies are more likely to occur than in VSG. ${ }^{72} \mathrm{An}$ other complication of MBS is gastro-esophageal reflux, which occurs more frequently with laparoscopic VSG than RYGB; 12\%$30 \%$ of patients require long-term use of proton pump inhibitors. ${ }^{79}$ All of these surgical procedures put patients at risk for leakage at the anastomosis site, hernia, stricture, and wound infection; however, those complications occur less frequently in pediatric patients than in adult patients. ${ }^{79}$

\section{CONCLUSION}

The number of children and adolescents with severe obesity in Korea has increased substantially; because its short- and long-term 
health consequences are unavoidable, severe pediatric obesity should be treated comprehensively. Furthermore, because accumulating evidence suggests that severe obesity in childhood is usually associated with adverse metabolic profiles, early screening for obesity-related comorbidities such as diabetes or hypertension should be recommended. By using early-life weight-gain trajectory data to differentiate young children who are at risk of developing severe obesity, clinicians could intervene early to reduce metabolic risk in adulthood. Family-based interventions in early life could be effective solutions to prevent severe pediatric obesity. The treatment options for children who have severe obesity include lifestyle modification therapy, pharmacological therapy, and bariatric surgery, but innovative therapies with progressively more intensive methods need to be developed and evaluated to improve outcomes for children afflicted with this disease.

To make meaningful progress, health professionals who treat pediatric obesity need to be aware of the causes and biological significance of severe obesity, and further research evaluating intensive treatment approaches is urgently needed. Also, those health professionals and public health officials must incorporate their area of expertise into public health programs and policies for childhood obesity to foster a community-based approach and develop and maintain obesity prevention programs for children and adolescents.

\section{CONFLICTS OF INTEREST}

The authors declare no conflict of interest.

\section{AUTHOR CONTRIBUTIONS}

Study concept and design: all authors; drafting of the manuscript: YLC; critical revision of the manuscript: all authors; study supervision: YJR.

\section{REFERENCES}

1. NCD Risk Factor Collaboration (NCD-RisC). Worldwide trends in body-mass index, underweight, overweight, and obesity from 1975 to 2016: a pooled analysis of 2416 populationbased measurement studies in 128.9 million children, adoles- cents, and adults. Lancet 2017;390:2627-42.

2. Kim JH, Moon JS. Secular trends in pediatric overweight and obesity in Korea. J Obes Metab Syndr 2020;29:12-7.

3. Skinner AC, Ravanbakht SN, Skelton JA, Perrin EM, Armstrong SC. Prevalence of obesity and severe obesity in US children, 1999-2016. Pediatrics 2018;141:e20173459.

4. Nam HK, Kim HR, Rhie YJ, Lee KH. Trends in the prevalence of extreme obesity among Korean children and adolescents from 2001 to 2014. J Pediatr Endocrinol Metab 2017; 30:517-23.

5. Rundle AG, Park Y, Herbstman JB, Kinsey EW, Wang YC. COVID-19-related school closings and risk of weight gain among children. Obesity (Silver Spring) 2020;28:1008-9.

6. Kang HM, Jeong DC, Suh BK, Ahn MB. The impact of the coronavirus disease-2019 pandemic on childhood obesity and vitamin D status. J Korean Med Sci 2021;36:e21.

7. Kim ES, Kwon Y, Choe YH, Kim MJ. COVID-19-related school closing aggravate obesity and glucose intolerance in pediatric patients with obesity. Sci Rep 2021;11:5494.

8. Han JA, Chung YE, Chung IH, Hong YH, Chung S. Impact of the COVID-19 pandemic on seasonal variations in childhood and adolescent growth: experience of pediatric endocrine clinics. Children (Basel) 2021;8:404.

9. McLaren L. Socioeconomic status and obesity. Epidemiol Rev 2007;29:29-48.

10. Shrewsbury V, Wardle J. Socioeconomic status and adiposity in childhood: a systematic review of cross-sectional studies 1990-2005. Obesity (Silver Spring) 2008;16:275-84.

11. Lee HJ, Kim SH, Choi SH, Lee JS. The association between socioeconomic status and obesity in Korean children: an analysis of the Fifth Korea National Health and Nutrition Examination Survey (2010-2012). Pediatr Gastroenterol Hepatol Nutr 2017;20:186-93.

12. Nam SY, Lee SK. The associations between socioeconomic status and obesity in Korean children from 1998 to 2009. Health 2013;5:1899-904.

13. Abbasi A, Juszczyk D, van Jaarsveld C, Gulliford MC. Body mass index and incident type 1 and type 2 diabetes in children and young adults: a retrospective cohort study. J Endocr Soc 2017;1:524-37. 
14. Vos MB, Abrams SH, Barlow SE, Caprio S, Daniels SR, Kohli $\mathrm{R}$, et al. NASPGHAN clinical practice guideline for the diagnosis and treatment of nonalcoholic fatty liver disease in children: recommendations from the Expert Committee on NAFLD (ECON) and the North American Society of Pediatric Gastroenterology, Hepatology and Nutrition (NASPGHAN). J Pediatr Gastroenterol Nutr 2017;64:319-34.

15. Turer CB, Brady TM, de Ferranti SD. Obesity, hypertension, and dyslipidemia in childhood are key modifiable antecedents of adult cardiovascular disease: a call to action. Circulation 2018;137:1256-9.

16. Wühl E. Hypertension in childhood obesity. Acta Paediatr 2019;108:37-43.

17. Calcaterra V, Klersy C, Muratori T, Telli S, Caramagna C, Scaglia F, et al. Prevalence of metabolic syndrome (MS) in children and adolescents with varying degrees of obesity. Clin Endocrinol (Oxf) 2008;68:868-72.

18. Gidding SS, Nehgme R, Heise C, Muscar C, Linton A, Hassink S. Severe obesity associated with cardiovascular deconditioning, high prevalence of cardiovascular risk factors, diabetes mellitus/hyperinsulinemia, and respiratory compromise. J Pediatr 2004;144:766-9.

19. Tounian P, Aggoun Y, Dubern B, Varille V, Guy-Grand B, Sidi $D$, et al. Presence of increased stiffness of the common carotid artery and endothelial dysfunction in severely obese children: a prospective study. Lancet 2001;358:1400-4.

20. Freedman DS, Mei Z, Srinivasan SR, Berenson GS, Dietz WH. Cardiovascular risk factors and excess adiposity among overweight children and adolescents: the Bogalusa Heart Study. J Pediatr 2007;150:12-7.

21. Buscot MJ, Thomson RJ, Juonala M, Sabin MA, Burgner DP, Lehtimäki T, et al. Distinct child-to-adult body mass index trajectories are associated with different levels of adult cardiometabolic risk. Eur Heart J 2018;39:2263-70.

22. Troiano RP, Flegal KM, Kuczmarski RJ, Campbell SM, Johnson CL. Overweight prevalence and trends for children and adolescents: the National Health and Nutrition Examination Surveys, 1963 to 1991. Arch Pediatr Adolesc Med 1995;149: 1085-91.

23. Whitaker RC, Wright JA, Pepe MS, Seidel KD, Dietz WH.
Predicting obesity in young adulthood from childhood and parental obesity. N Engl J Med 1997;337:869-73.

24. Dietz WH, Robinson TN. Use of the body mass index (BMI) as a measure of overweight in children and adolescents. J Pediatr 1998;132:191-3.

25. Skinner AC, Perrin EM, Moss LA, Skelton JA. Cardiometabolic risks and severity of obesity in children and young adults. N Engl J Med 2015;373:1307-17.

26. Kelly AS, Barlow SE, Rao G, Inge TH, Hayman LL, Steinberger J, et al. Severe obesity in children and adolescents: identification, associated health risks, and treatment approaches: a scientific statement from the American Heart Association. Circulation 2013;128:1689-712.

27. Li S, Chen W, Srinivasan SR, Bond MG, Tang R, Urbina EM, et al. Childhood cardiovascular risk factors and carotid vascular changes in adulthood: the Bogalusa Heart Study. JAMA 2003;290:2271-6.

28. Reaven GM. Pathophysiology of insulin resistance in human disease. Physiol Rev 1995;75:473-86.

29. Brown MS, Goldstein JL. Selective versus total insulin resistance: a pathogenic paradox. Cell Metab 2008;7:95-6.

30. Perry RJ, Samuel VT, Petersen KF, Shulman GI. The role of hepatic lipids in hepatic insulin resistance and type 2 diabetes. Nature 2014;510:84-91.

31. Kim SP, Catalano KJ, Hsu IR, Chiu JD, Richey JM, Bergman RN. Nocturnal free fatty acids are uniquely elevated in the longitudinal development of diet-induced insulin resistance and hyperinsulinemia. Am J Physiol Endocrinol Metab 2007; 292:E1590-8.

32. Ginsberg HN, Zhang YL, Hernandez-Ono A. Regulation of plasma triglycerides in insulin resistance and diabetes. Arch Med Res 2005;36:232-40.

33. Samuel VT, Shulman GI. The pathogenesis of insulin resistance: integrating signaling pathways and substrate flux. J Clin Invest 2016;126:12-22.

34. Large V, Arner P. Regulation of lipolysis in humans. Pathophysiological modulation in obesity, diabetes, and hyperlipidaemia. Diabetes Metab 1998;24:409-18.

35. Hershkop K, Besor O, Santoro N, Pierpont B, Caprio S, Weiss $\mathrm{R}$. Adipose insulin resistance in obese adolescents across the 
spectrum of glucose tolerance. J Clin Endocrinol Metab 2016; 101:2423-31.

36. Sinha R, Dufour S, Petersen KF, LeBon V, Enoksson S, Ma $\mathrm{YZ}$, et al. Assessment of skeletal muscle triglyceride content by (1) $\mathrm{H}$ nuclear magnetic resonance spectroscopy in lean and obese adolescents: relationships to insulin sensitivity, total body fat, and central adiposity. Diabetes 2002;51:1022-7.

37. Weiss R, Dufour S, Taksali SE, Tamborlane WV, Petersen KF, Bonadonna RC, et al. Prediabetes in obese youth: a syndrome of impaired glucose tolerance, severe insulin resistance, and altered myocellular and abdominal fat partitioning. Lancet 2003;362:951-7.

38. Sharma AM, Padwal R. Obesity is a sign: over-eating is a symptom. An aetiological framework for the assessment and management of obesity. Obes Rev 2010;11:362-70.

39. Olney RC, Mougey EB. Expression of the components of the insulin-like growth factor axis across the growth-plate. Mol Cell Endocrinol 1999;156:63-71.

40. Han JC, Weiss R. Obesity, metabolic syndrome and disorders of energy balance. In: Sperling MA, editor. Sperling pediatric endocrinology. 5th ed. Philadelphia (PA): Elsevier; 2021. p. 939-1003.

41. Min J, Chiu DT, Wang Y. Variation in the heritability of body mass index based on diverse twin studies: a systematic review. Obes Rev 2013;14:871-82.

42. Fairbrother U, Kidd E, Malagamuwa T, Walley A. Genetics of severe obesity. Curr Diab Rep 2018;18:85.

43. Farooqi IS, O'Rahilly S. Mutations in ligands and receptors of the leptin-melanocortin pathway that lead to obesity. Nat Clin Pract Endocrinol Metab 2008;4:569-77.

44. Chen KY, Muniyappa R, Abel BS, Mullins KP, Staker P, Brychta RJ, et al. RM-493, a melanocortin-4 receptor (MC4R) agonist, increases resting energy expenditure in obese individuals. J Clin Endocrinol Metab 2015;100:1639-45.

45. Gross AC, Fox CK, Rudser KD, Foy AM, Kelly AS. Eating behaviours are different in youth with obesity and severe obesity. Clin Obes 2016;6:68-72.

46. St-Onge MP. Sleep-obesity relation: underlying mechanisms and consequences for treatment. Obes Rev 2017;18 Suppl 1:34-9.

47. Geiker N, Astrup A, Hjorth MF, Sjödin A, Pijls L, Markus
CR. Does stress influence sleep patterns, food intake, weight gain, abdominal obesity and weight loss interventions and vice versa? Obes Rev 2018;19:81-97.

48. Puder JJ, Munsch S. Psychological correlates of childhood obesity. Int J Obes (Lond) 2010;34 Suppl 2:S37-43.

49. Fox CK, Gross AC, Rudser KD, Foy AM, Kelly AS. Depression, anxiety, and severity of obesity in adolescents: is emotional eating the link? Clin Pediatr (Phila) 2016;55:1120-5.

50. Bauer KW, Marcus MD, Larson N, Neumark-Sztainer D. Socioenvironmental, personal, and behavioral correlates of severe obesity among an ethnically/racially diverse sample of US adolescents. Child Obes 2017;13:470-8.

51. Zeller MH, Inge TH, Modi AC, Jenkins TM, Michalsky MP, Helmrath M, et al. Severe obesity and comorbid condition impact on the weight-related quality of life of the adolescent patient. J Pediatr 2015;166:651-9.

52. Puhl RM, Peterson JL, Luedicke J. Weight-based victimization: bullying experiences of weight loss treatment-seeking youth. Pediatrics 2013;131:e1-9.

53. Danielsson P, Kowalski J, Ekblom Ö, Marcus C. Response of severely obese children and adolescents to behavioral treatment. Arch Pediatr Adolesc Med 2012;166:1103-8.

54. Bravata DM, Sanders L, Huang J, Krumholz HM, Olkin I, Gardner CD, et al. Efficacy and safety of low-carbohydrate diets: a systematic review. JAMA 2003;289:1837-50.

55. Suskind RM, Blecker U, Udall JN Jr, von Almen TK, Schumacher HD, Carlisle L, et al. Recent advances in the treatment of childhood obesity. Pediatr Diabetes 2000;1:23-33.

56. Berkowitz RI, Wadden TA, Gehrman CA, Bishop-Gilyard CT, Moore RH, Womble LG, et al. Meal replacements in the treatment of adolescent obesity: a randomized controlled trial. Obesity (Silver Spring) 2011;19:1193-9.

57. Lobelo F, Muth ND, Hanson S, Nemeth BA; Council on Sports Medicine and Fitness; Section on Obesity. Physical activity assessment and counseling in pediatric clinical settings. Pediatrics 2020;145:e20193992.

58. Styne DM, Arslanian SA, Connor EL, Farooqi IS, Murad MH, Silverstein JH, et al. Pediatric obesity-assessment, treatment, and prevention: an Endocrine Society clinical practice guideline. J Clin Endocrinol Metab 2017;102:709-57. 
59. Wickham EP 3rd, DeBoer MD. Evaluation and treatment of severe obesity in childhood. Clin Pediatr (Phila) 2015;54:929-40.

60. Srivastava G, Fox CK, Kelly AS, Jastreboff AM, Browne AF, Browne NT, et al. Clinical considerations regarding the use of obesity pharmacotherapy in adolescents with obesity. Obesity (Silver Spring) 2019;27:190-204.

61. Chanoine JP, Hampl S, Jensen C, Boldrin M, Hauptman J. Effect of orlistat on weight and body composition in obese adolescents: a randomized controlled trial. JAMA 2005;293: 2873-83.

62. Maahs D, de Serna DG, Kolotkin RL, Ralston S, Sandate J, Qualls C, et al. Randomized, double-blind, placebo-controlled trial of orlistat for weight loss in adolescents. Endocr Pract 2006; 12:18-28.

63. Ryder JR, Kaizer A, Rudser KD, Gross A, Kelly AS, Fox CK. Effect of phentermine on weight reduction in a pediatric weight management clinic. Int J Obes (Lond) 2017;41:90-3.

64. Masarwa R, Brunetti VC, Aloe S, Henderson M, Platt RW, Filion KB. Efficacy and safety of metformin for obesity: a systematic review. Pediatrics 2021;147:e20201610.

65. O’Connor EA, Evans CV, Burda BU, Walsh ES, Eder M, Lozano P. Screening for obesity and intervention for weight management in children and adolescents: evidence report and systematic review for the US Preventive Services Task Force. JAMA 2017;317:2427-44.

66. Kelly AS, Metzig AM, Rudser KD, Fitch AK, Fox CK, Nathan BM, et al. Exenatide as a weight-loss therapy in extreme pediatric obesity: a randomized, controlled pilot study. Obesity (Silver Spring) 2012;20:364-70.

67. Kelly AS, Rudser KD, Nathan BM, Fox CK, Metzig AM, Coombes BJ, et al. The effect of glucagon-like peptide-1 receptor agonist therapy on body mass index in adolescents with severe obesity: a randomized, placebo-controlled, clinical trial. JAMA Pediatr 2013;167:355-60.

68. Weghuber D, Forslund A, Ahlström H, Alderborn A, Bergström K, Brunner S, et al. A 6-month randomized, doubleblind, placebo-controlled trial of weekly exenatide in adolescents with obesity. Pediatr Obes 2020;15:e12624.

69. Kelly AS, Auerbach P, Barrientos-Perez M, Gies I, Hale PM, Marcus C, et al. A randomized, controlled trial of liraglutide for adolescents with obesity. N Engl J Med 2020;382:2117-28.

70. Zoicas F, Droste M, Mayr B, Buchfelder M, Schöfl C. GLP-1 analogues as a new treatment option for hypothalamic obesity in adults: report of nine cases. Eur J Endocrinol 2013;168: 699-706.

71. Kim YM, Lee YJ, Kim SY, Cheon CK, Lim HH. Successful rapid weight reduction and the use of liraglutide for morbid obesity in adolescent Prader-Willi syndrome. Ann Pediatr Endocrinol Metab 2020;25:52-6.

72. Pratt J, Browne A, Browne NT, Bruzoni M, Cohen M, Desai A, et al. ASMBS pediatric metabolic and bariatric surgery guidelines, 2018. Surg Obes Relat Dis 2018;14:882-901.

73. Inge TH, Courcoulas AP, Jenkins TM, Michalsky MP, Helmrath MA, Brandt ML, et al. Weight loss and health status 3 years after bariatric surgery in adolescents. $\mathrm{N}$ Engl J Med 2016;374:113-23.

74. Inge TH, Jenkins TM, Xanthakos SA, Dixon JB, Daniels SR, Zeller $\mathrm{MH}$, et al. Long-term outcomes of bariatric surgery in adolescents with severe obesity (FABS-5+): a prospective follow-up analysis. Lancet Diabetes Endocrinol 2017;5:165-73.

75. Olbers T, Beamish AJ, Gronowitz E, Flodmark CE, Dahlgren J, Bruze G, et al. Laparoscopic Roux-en-Y gastric bypass in adolescents with severe obesity (AMOS): a prospective, 5-year, Swedish nationwide study. Lancet Diabetes Endocrinol 2017; 5:174-83.

76. Ryder JR, Gross AC, Fox CK, Kaizer AM, Rudser KD, Jenkins TM, et al. Factors associated with long-term weight-loss maintenance following bariatric surgery in adolescents with severe obesity. Int J Obes (Lond) 2018;42:102-7.

77. Scheimann AO, Miller J, Glaze DG. Laparoscopic sleeve gastrectomy in children and adolescents with Prader-Willi syndrome: a matched control study. Surg Obes Relat Dis 2017; $13: 366$.

78. Censani M, Conroy R, Deng L, Oberfield SE, McMahon DJ, Zitsman JL, et al. Weight loss after bariatric surgery in morbidly obese adolescents with MC4R mutations. Obesity (Silver Spring) 2014;22:225-31.

79. Inge TH, Krebs NF, Garcia VF, Skelton JA, Guice KS, Strauss RS, et al. Bariatric surgery for severely overweight adolescents: concerns and recommendations. Pediatrics 2004;114:217-23. 